\title{
Cerebrovascular expression of proteins related to inflammation, oxidative stress and neurotoxicity is altered with aging
}

\author{
Debjani Tripathy, Xiangling Yin, Alma Sanchez, Jinhua Luo, Joseph Martinez, Paula Grammas*
}

\begin{abstract}
Background: Most neurodegenerative diseases are age-related disorders; however, how aging predisposes the brain to disease has not been adequately addressed. The objective of this study is to determine whether expression of proteins in the cerebromicrovasculature related to inflammation, oxidative stress and neurotoxicity is altered with aging.

Methods: Brain microvessels are isolated from Fischer 344 rats at 6, 12, 18 and 24 months of age. Levels of interleukin (IL)-1 $\beta$ and IL-6 RNA are determined by RT-PCR and release of cytokines into the media by ELISA. Vessel conditioned media are also screened by ELISA for IL-1 $\alpha$, monocyte chemoattractant protein-1 (MCP-1), tumor necrosis factor- $\alpha$, (TNF $\alpha)$, and interferon $\gamma$ (IFN $\gamma$ ). Immunofluorescent analysis of brain sections for IL-1 $\beta$ and IL-6 is performed.
\end{abstract}

Results: Expression of IL-1 $\beta$ and IL-6, both at RNA and protein levels, significantly $(p<0.01)$ decreases with age. Levels of MCP-1, TNF $\alpha, \mathrm{IL}-1 \alpha$, and IFN $\gamma$ are significantly ( $p<0.05-0.01$ ) lower in 24 month old rats compared to 6 month old animals. Immunofluorescent analysis of brain vessels also shows a decline in IL-1 $\beta$ and IL-6 in aged rats. An increase in oxidative stress, assessed by increased carbonyl formation, as well as a decrease in the antioxidant protein manganese superoxide dismutase (MnSOD) is evident in vessels of aged animals. Finally, addition of microvessel conditioned media from aged rats to neuronal cultures evokes significant $(p<0.001)$ neurotoxicity.

Conclusions: These data demonstrate that cerebrovascular expression of proteins related to inflammation, oxidative stress and neurotoxicity is altered with aging and suggest that the microvasculature may contribute to functional changes in the aging brain.

\section{Background}

Diseases of the CNS are for the most part age-associated disorders. A direct relationship exists between aging and increasing incidence of neurodegenerative disease [1]. In age-associated diseases inflammation and oxidative damage are important features of brain pathology and are often found together [2]. Despite a large body of data linking inflammation and oxidative stress to the pathology in age-related diseases, there is insufficient knowledge about the effects of aging alone, in the absence of disease, on inflammatory mediators and oxidative stress in the brain.

\footnotetext{
* Correspondence: paula.grammas@ttuhsc.edu

Garrison Institute on Aging, Texas Tech University Health Sciences Center, Lubbock, Texas
}

(c) 2010 Tripathy et al; licensee BioMed Central Ltd. This is an Open Access article distributed under the terms of the Creative Commons Attribution License (http://creativecommons.org/licenses/by/2.0), which permits unrestricted use, distribution, and reproduction in any medium, provided the original work is properly cited.
An age-related increase in plasma and circulating levels of tumor necrosis factor - alpha (TNF $\alpha)$, interleukin-1 beta (IL-1 $\beta$ ), interleukin-6 (IL-6), tumor necrosis factor receptor (TNFRs) and interleukin-1 receptor antagonist (IL-1RA) [3-6] has been shown in some studies, while other investigations show no age-related increases in TNFa or IL-6 [7,8]. Similarly, an increase in IL-6 is reported in a randomly selected population of elderly Americans (70 and above) but not in a population identified as "strictly healthy" [7]. Twenty-four hour lipopolysaccharide (LPS) stimulation of whole blood supernatants finds lower levels of TNF $\alpha$ and IL- $1 \beta$ but not IL-6 in samples derived from elderly compared to young control samples [9]. Animal studies comparing young and aged rodents show a decrease in chemokine expression in a dermal injury model but an increase in 
pro-inflammatory cytokine expression in coronary arteries in aged animals $[10,11]$. In addition, there is disparity between cellular responsiveness and circulating plasma levels. There is an increase in serum kinin levels with aging but aortic endothelial cells from old Fischer 344 rats are hyporesponsive to exogenous bradykinin [12]. In human studies, IL-6, but not IL- $1 \beta$ and TNF $\alpha$ production by peripheral mononuclear cells is increased in aged subjects compared to young cohorts [13]. The effect of aging on the expression of cytokines and chemokines is controversial and inconsistent. In part, these discrepancies could reflect heterogeneity among different tissues examined. There is an increase in pro-inflamatory cytokine expression, detected by microarray, in coronary vessels of 25 month old Fischer 344 rats compared to vessels of young rats [10]. In contrast, a study examining the myocardial response to infarction in senescent mice shows a decrease in neutrophil and macrophage infiltration and reduced cytokine and chemokine expression in myocardial tissues compared to young mice [14].

Oxidative stress, which results from an imbalance between reactive oxygen species generation and antioxidant enzyme capacity, is particularly important for the brain because of its high metabolic rate. A number of indices of oxidative stress such as protein oxidation, lipid peroxidation, DNA oxidation and 3-nitrotyrosine formation as well as diminished levels of antioxidants such as superoxide dismutase (SOD) have been documented in neurodegenerative diseases [15]. In aging an increase in the amount of oxidized proteins has been reported, as measured by the level of intracellular protein carbonyls or nitrotyrosine [16]. Evidence from a number of studies shows aging-associated accumulation of oxidatively damaged DNA in the brain and other organs with limited cell proliferation [17].

The brain microvasculature appears to be a site of convergence for inflammatory and oxidative processes in neurodegenerative disease. Isolated brain microvessels obtained from Alzheimer's disease (AD) patients have high levels of both cell-associated and soluble cytokines and chemokines including IL-1 $\beta$, IL-6, IL-8, TNF $\alpha$, transforming growth factor- $\beta$ (TGF- $\beta$ ) and monocyte chemoattractant protein-1 (MCP-1) compared to age-matched non-AD controls [18-20]. Also, in AD a damaged microcirculation releases high levels of the reactive oxygen species nitric oxide [21]. Finally, we document that in AD dysfunctional microvessels release factors that are directly injurious to neurons in culture [22]. Although age is the dominant risk factor for the development of neurodegenerative disease, the effect of aging on inflammatory, oxidative and neurotoxic processes in the brain microvasculature has not been explored. The possibility that the cerebromicrovasculature is functionally altered in aging is suggested by data showing that microvessels or vessel-conditioned media from elderly non-demented patients, although significantly less lethal than AD-derived vessels, injures neurons in vitro [22].

The objective of the current study is to determine whether expression of proteins in the cerebromicrovasculature related to inflammation, oxidative stress or neurotoxicity are altered in an animal model of aging.

\section{Materials and methods}

\section{Microvessel isolation and preparation of conditioned media}

Animal procedures were performed in accordance with $\mathrm{NIH}$ "Guide for the Care and Use of Laboratory Animals" and Texas Tech University Health Sciences Center Institutional Animal Care and Use Committee (IACUC) guidelines. Male Fisher rats 344 6, 12, 18 and 24 month old were purchased from NIA. The rats weighed approximately 450 to $500 \mathrm{~g}$. Upon delivery they were housed in individual ventilated cages with bedding and free access to water for a week prior to microvessel isolation. Each age group consists of 24 male Fisher 344 rats and the microvessel isolation performed in triplicate [23]. Cerebral cortices were homogenized in cold Hank's balanced salt solution (HBSS) without calcium and the homogenate centrifuged at $3000 \mathrm{~g}$ for $15 \mathrm{~min}$ at $4^{\circ} \mathrm{C}$. The pellet was resuspended in cold HBSS containing $15 \%$ dextran and $5 \%$ fetal bovine serum (FBS) and centrifuged at $4500 \mathrm{~g}$ for $20 \mathrm{~min}$ at $4{ }^{\circ} \mathrm{C}$. The supernatant discarded and the pellet filtered through a $150 \mu \mathrm{m}$ sieve and microvessels collected on a $53 \mu \mathrm{m}$ sieve. Microvessels were resupended in Dulbecco's modified Eagle's medium (DMEM) containing 10\% FBS and dimethyl sulfoxide and stored frozen in liquid nitrogen until use. The purity of the microvessel preparations was assessed by phase contrast microscopy.

Microvessels from 6,12,18 and 24 month old rats were thawed and centrifuged at $2000 \mathrm{~g}$ for $15 \mathrm{~min}$. Microvessels $(50 \mu \mathrm{g} / \mathrm{sample})$ were washed three times with cold HBSS and resuspended in $500 \mu \mathrm{l}$ serum-free DMEM containing $1 \%$ lactalbumin hydrolysate (LAH) for $8 \mathrm{~h}$ at $37^{\circ} \mathrm{C}$ in a $95 \% \mathrm{CO}_{2} / 5 \% \mathrm{O}_{2}$ incubator and then centrifuged (2000 g). Supernatants were collected for neurotoxicity analysis and determination of inflammatory proteins.

\section{Cerebral cortical cell culture and measurement of neuronal cell death}

Rat cerebral cortical cell cultures were prepared as previously described [22,24]. Cortices were isolated from 17day gestation rat fetuses, washed with HBSS, triturated in $10 \mathrm{ml}$ Brooks-Logan solution containing 0.025\% trypsin and centrifuged for $10 \mathrm{~min}$ at $800 \mathrm{~g}$. The supernatant was discarded and the pellet was triturated and filtered 
through a $210 \mu \mathrm{m}$ mesh. The cells were plated at a density of $500,000 / \mathrm{ml}$ in media containing DMEM supplemented with $2 \mathrm{mM}$

L-glutamine, $10 \%$ heat-inactivated horse serum, and antibiotic/antimycotic on 6-well plates coated with polyL-lysine. Experimental treatments were carried out on day 8 in Neurobasal medium containing $\mathrm{N}-2$ supplement, $0.5 \mathrm{mM} \mathrm{L}$-glutamine and antibiotic/antimycotic (treatment medium).

For the neurotoxicity assay, cerebral cortical cell cultures were incubated with $100 \mu \mathrm{l}$ conditioned media for $24 \mathrm{~h}$. Neuronal cells were washed with phosphate buffered saline (PBS) and incubated with the MTT reagent 3-(4, 5-dimethylthiazol-2-yl)-2-5-diphenyl tetrazolium bromide reagent (1:40 dilution) for $5-10 \mathrm{~min}$ at $37^{\circ} \mathrm{C}$. The formazon product, which is produced only by live cells, was quantified by colorimetric assay at $490 \mathrm{~nm}$ (Cell Titer 95 Aqueous solution cell proliferation assay, Promega, Madison, WI). In each experiment, the number of control cells i.e. viable cells not exposed to any treatment was defined as $100 \%$.

\section{Measurement of protein carbonyl content}

Protein carbonyl content in microvessels was determined using the OxyBlot protein oxidation detection kit (Chemicon, Temecula, CA). Proteins extracted from brain microvessels from $6,12,18$ and 24 month old rats were quantified using Bradford reagent. Equal amounts of protein $(5 \mu \mathrm{l})$ were denatured by adding $5 \mu \mathrm{l}$ of $12 \%$ SDS. The proteins were derivatized by adding $10 \mu \mathrm{l}$ of 2 , 4 dinitrophenylhydrazine (DNPH). The derivatization control solution without DNPH served as negative control. The samples were incubated at room temperature for $15 \mathrm{~min}$ and neutralized with equal amounts of neutralization solution. Both the treated sample and the negative control were subjected to dot blot analysis. Oxidized proteins were detected with anti-DNPH antibodies provided in the kit. Band intensities were quantified using the Quanitity One software (Bio-Rad) and represented as relative units.

\section{Detection of inflammatory proteins by ELISA and RT-PCR} IL- 6 and IL-1 $\beta$ released into the supernatant were detected with rat custom 9 plex SL4638 Search Light sample testing service (Pierce Biotechnology, MA). To confirm the testing service results ELISA measurements were performed for IL-1 $\beta$ using ELISA kit RLB00 (R\&D Systems, $\mathrm{MN})$, according to manufacturer's instructions. Monocyte chemotactic protein-1 (MCP-1), TNF $\alpha$, interferon $\gamma$ (IFN $\gamma$ ) and IL-1 $\alpha$ were also determined by the rat custom 9 plex SL4638 Search Light sample testing service.

Total RNA was isolated from rat brain microvessels with Trizol reagent (Invitrogen, Carlsbad, CA) and $1 \mu \mathrm{g}$ of RNA was reverse transcribed using oligo dT primers
(Roche Applied Science) and amplified by PCR. PCR amplification was performed with cDNA, gene specific primers (Table 1) as follows: denaturation for $2 \mathrm{~min}$ at $95^{\circ} \mathrm{C}, 30$ cycles of $95^{\circ} \mathrm{C}$ for $40 \mathrm{sec}, 55^{\circ} \mathrm{C}$ for $40 \mathrm{sec}$ and $72^{\circ} \mathrm{C}$ for $2 \mathrm{~min}$ and a final extension at $72^{\circ} \mathrm{C}$ for $5 \mathrm{~min}$. The PCR products were visualized in a 1.5\% agarose gel containing $0.5 \mu \mathrm{g} / \mathrm{ml}$ ethidium bromide under UV trans-illumination light with a gel documentation system (Quantity One analysis software, Bio-Rad).

\section{Western Blot determination of MnSOD}

Total protein was extracted from microvessels with lysis buffer containing $0.1 \%$ SDS, $1 \%$ Triton X-100 and 0.5\% phenylmethyl sulfonylfluoride. Protein estimation was performed with Bradford reagent (Bio-Rad). Equal amounts of protein were run on a $12 \%$ polyacrylamide gel, transferred on to a PVDF membrane, blocked with $5 \%$ milk solution (non-fat dry milk in Tris-buffered saline Tween-20) and immuno-blotted with MnSOD (ab 16956,1:1000) and GAPDH (MAB374, 1:1000) primary antibodies for $2 \mathrm{~h}$. Membranes were washed with Trisbuffered saline Tween-20 and incubated for $1 \mathrm{~h}$ with peroxidase- conjugated secondary antibodies. After extensive washing to remove unbound antibodies, membranes were developed with chemiluminescence reagents. Band intensities were quantitified using Quantity One software (Bio-Rad) and graphically expressed as intensity units which reflects the average intensity over the area of the band normalized with that of GAPDH.

\section{Immunofluorescence staining of brain tissue sections}

Immunofluorescence labeling of rat brain tissue sections was performed as described previously [25]. Briefly paraffin sections $(5 \mu \mathrm{m})$ were deparaffinized and rehydrated in ethyl alcohol (100\% to $70 \%)$. After heat-induced epitope antigen retrieval, sections were washed in Tris-buffered saline with Tween (TBST), blocked with $10 \%$ donkey serum at room temperature for $2 \mathrm{~h}$ and sections incubated at $4^{\circ} \mathrm{C}$ overnight with primary antibodies against: IL-1 $\beta$ (1:50, sc-7884, Santa Cruz Biotechnology, CA), IL-6 (1:50, sc-1265-R, Santa Cruz Biotechnology, CA), MnSOD (1:200, ab16956, Abcam) or Von Willebrand Factor (VWF) (1:50, sc-8068, Santa Cruz

\section{Table 1 Primers used for RT-PCR}

\begin{tabular}{cclc}
\hline Gene & Orientation & Sequence & $\begin{array}{c}\text { Amplicon } \\
\text { Size (bp) }\end{array}$ \\
\hline IL-1 $\beta$ & Left primer & AGCAGCTITCGACAGTGAGGAGAA & 182 \\
& Right primer & TCTCCACAGCCACAATGAGTGACA & \\
\hline IL-6 & Left primer & CCGGAGAGGAGACTTCACAG & 428 \\
& Right primer & GAGCATTGGAGTTGGGGTA & \\
\hline GAPDH & Left primer & TCTGCATCTGGCAAAGTGGAGACT & 101 \\
& Right primer & TTGAACTTGCCGTGGGTAGAGTCA & \\
\hline
\end{tabular}


Biotechnology, CA) in TBS containing 2.5\% donkey serum. Following three washes with TBST, sections were incubated with FITC conjugated secondary antibodies (1:400, Invitrogen, Carlsbad, CA) at room temperature for $1 \mathrm{~h}$. All sections were counter stained with nuclear marker DAPI (blue). Fluorescent images were captured using an Olympus IX71 microscope and quantified with HAMAMATSU imaging software.

\section{Statistical analysis}

Data from each experiment were expressed as mean \pm standard deviation (SD). A one-way ANOVA followed by Bonferroni's multiple comparison tests for multiple samples were performed. Statistical significance was determined at $\mathrm{p}<0.05$.

\section{Results}

Microvessel-conditioned media from aged rats caused neuronal cell death

Based on our previous work showing that microvessels isolated from the brains of $\mathrm{AD}$ patients release neurotoxic factors [22], we examined the ability of isolated brain microvessels to cause neuronal cell death as a function of age. Microvessels isolated from Fischer 344 rats of $6,12,18$, and 24 months of age were incubated in serum free media for $8 \mathrm{~h}$ and the conditioned media added to primary cortical cultures for $24 \mathrm{~h}$. The results showed that with increasing age conditioned media from brain vessels evoked neuronal cell death. The ability of vessels to cause neuronal cell death was significant $(\mathrm{p}<0.01)$ at 18 months of age (Figure 1).

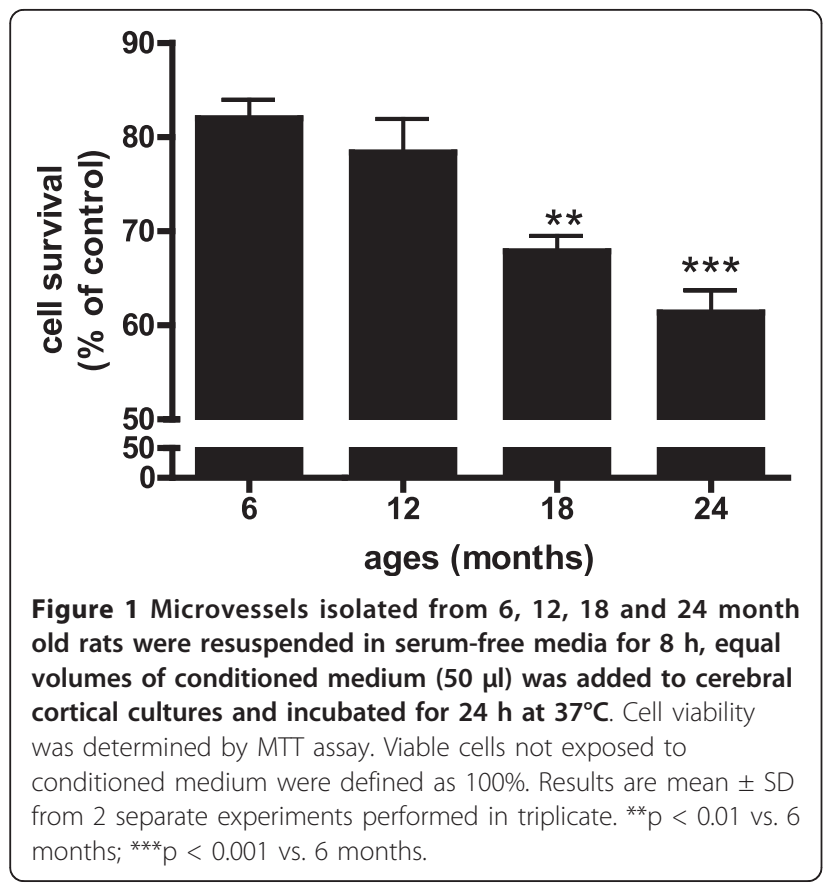

Aging increased oxidative stress and decreased antioxidants in brain microvasculature

The oxidative modification of proteins by reactive oxygen species can be quantitated by measurement of protein carbonyl content. In the current study protein lysates from brain microvessels isolated from 6, 12, 18 and 24 month old rats were derivatized with 2,4 dinitrophenyl hydrazine. Dot blot analysis using an antibody to DNPH showed an increase in vascular oxidative stress with age (Figure 2a). Densitometric scan of the data demonstrated that this increase was significant $(\mathrm{p}<$ 0.01 ) in animals 24 months of age (Figure $2 \mathrm{~b}$ ).

Because increased oxidative stress could reflect increased radical generation, diminished antioxidant capacity or both, we explored the vascular expression of the antioxidant protein MnSOD in brain sections of rats at 6 and 24 months of age. Immunofluorescent results showed that reactivity to the MnSOD antibody was clearly evident, as demonstrated by fluorescence (green) staining in the blood vessels walls of animals 6 months of age (Figure 3). In contrast, blood vessels from animals 24 months of age show little to no detectable staining for MnSOD.

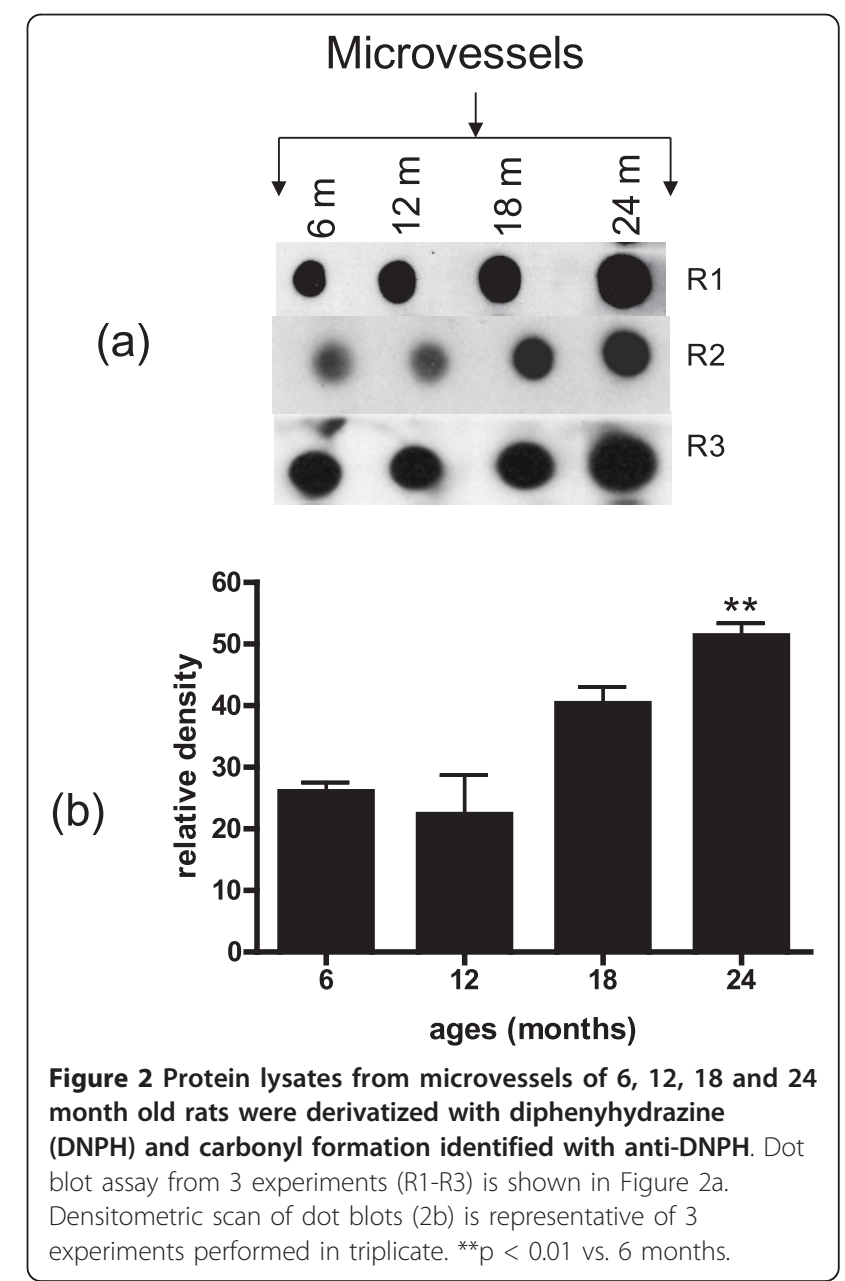




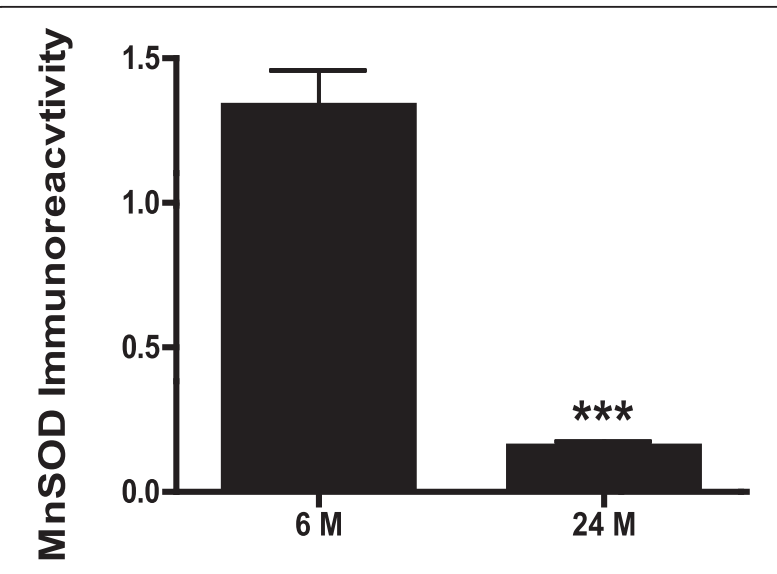

6 month
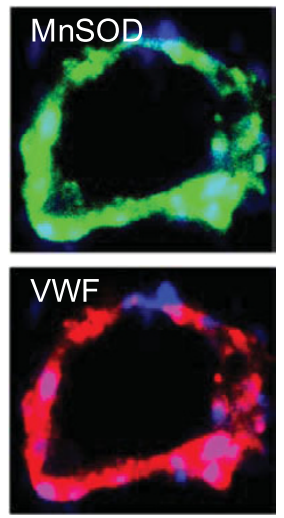

\section{4 month}
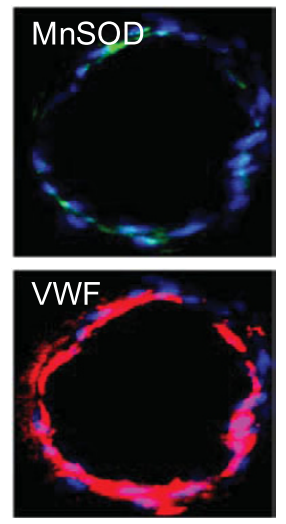

Figure 3 Brain tissue sections from 6 and 24 month old Fisher 344 rats were stained for nuclear stain DAPI (blue) and either MnSOD (green) or the endothelial cell specific marker VWF (red). Quantitative comparison of MnSOD expression between vessels derived from 6 month and 24 month old animals is shown in bar graph. Data are mean $\pm S D(n=6) . \times 20 .{ }^{* * *} p<0.001$ vs. 6 months.

Quantification of MnSOD staining (Figure 3) confirmed a significant $(p<0.001)$ decrease in enzyme expression in vessels from old animals compared to vessels of young animals. These results were further confirmed by western blot (Figure 4). Expression of MnSOD examined in microvessels from rats $6,12,18$, and 24 months of age showed a decrease in MnSOD level that was significant $(\mathrm{p}<0.01)$ at 18 months of age (Figure 4).

\section{Brain vascular expression of inflammatory proteins decreased with age}

We examined the ability of brain microvessels isolated from rats of different ages $(6,12,18,24$ months) to release the cytokines IL-1 $\beta$ and IL-6. Brain microvessels isolated from these animals were incubated in serumfree-media for $8 \mathrm{~h}$ and the media collected and assayed

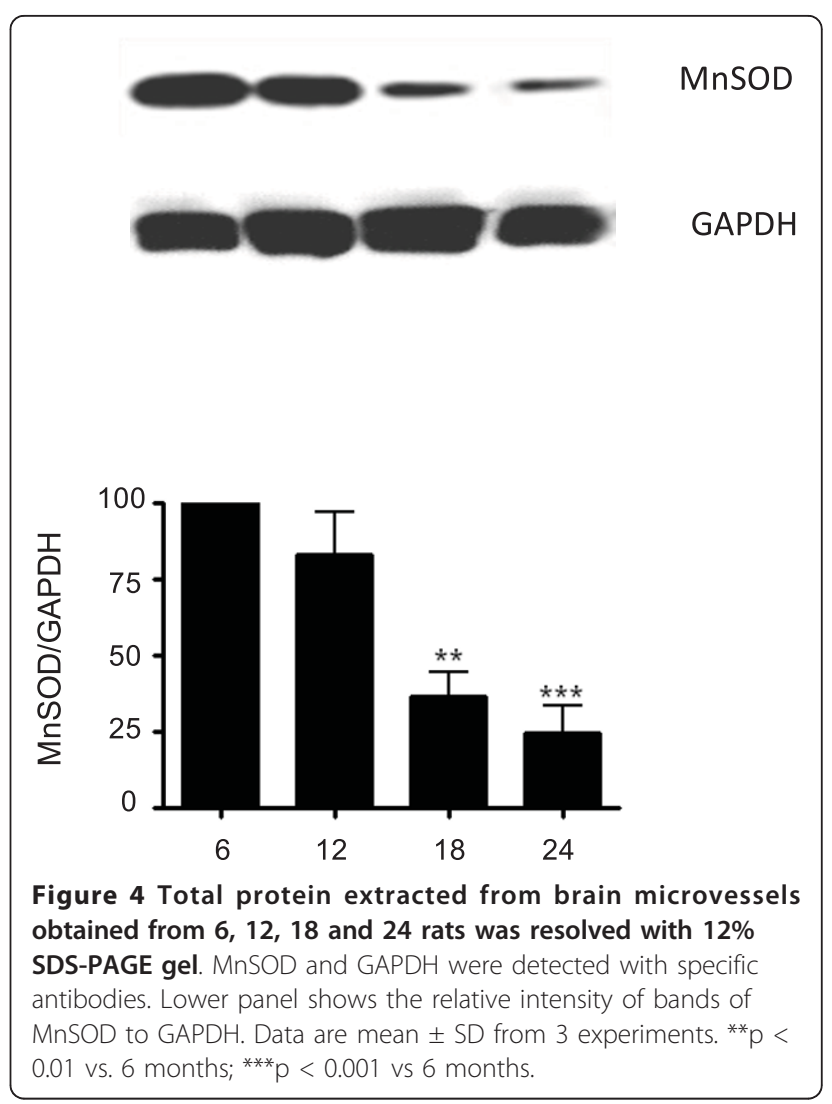

by ELISA for IL-1 $\beta$ and IL- 6 . The amount of vascularderived IL-1 $\beta$ showed a progressive decrease from 6 months to 24 months of age. This decrease was significant at 12 months $(\mathrm{p}<0.01)$ and highly significant at 18 and 24 months of age $(\mathrm{p}<0.001)$ (Figure 5a). Similarly, release of IL- 6 showed an age-dependent decrease, with large $(90 \%)$ and significant $(\mathrm{p}<0.01)$ decrease at 24 months of age (Figure 5b).

An examination of cytokine expression at the RNA level confirmed an age-dependent decrease in mRNA for IL-1 $\beta$ (Figure 6a) and IL-6 (Figure 6b) when compared to the expression of the housekeeping gene GAPDH.

To further confirm these data, we examined the expression of IL- $1 \beta$ and IL- 6 protein in tissue sections using immunofluorescent staining. The results indicated that reactivity to the antibody for IL- $1 \beta$ was intense in blood vessels from rats 6 months of age but significantly $(\mathrm{p}<0.01)$ less $(64.2 \%)$ in blood vessels from rats 24 months of age (Figure 7 ). Results obtained with antibody to IL-6 also indicated intense green fluorescent labeling in blood vessels from young rats (6 months of age), whereas staining was significantly $(\mathrm{p}<0.05)$ lower in vessel walls from animals 24 months of age (Figure 8 ).

An examination of microvessel-conditioned media from rats $6,12,18$ and 24 months of age for levels of inflammatory proteins IL-1 $\alpha$, MCP-1, TNF $\alpha$, and IFN- $\gamma$ 

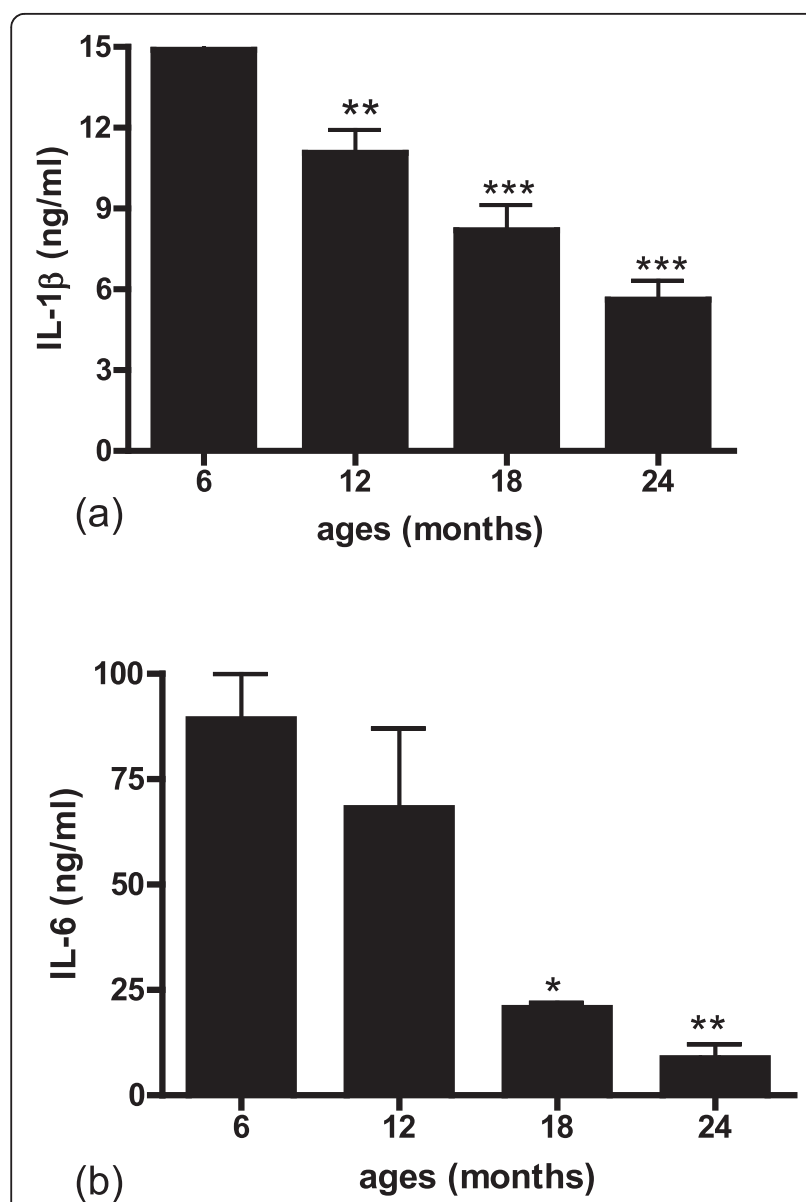

Figure 5 Microvessels isolated from 6, 12, 18 and 24 month old rat brains were incubated for $8 \mathrm{~h}$ in serum-free media and the supernatant centrifuged $(12,000 \mathbf{~ g}, 15 \mathrm{~min}) . \mathrm{IL}-1 \beta(5 \mathrm{a})$ and IL-6 $(5 b)$ released into the supernatant were determined using rat custom 9 plex array ELISA (Pierce Biotechnology, MA). For IL-1 $\beta$, ELISA was also performed using a kit from $R<D$ Systems. Data are mean \pm SD from 3 experiments performed in triplicate. ${ }^{*} p<0.05$ vs. 6 months; ${ }^{* *} p<0.01$ vs. 6 months; ${ }^{* *} p<0.001$ vs. 6 months.

showed a significant $(\mathrm{p}<0.05-0.01)$ decline in these proteins as animals aged (Table 2 ).

\section{Discussion}

Results from the current study indicate that expression and release of cytokines IL-1 $\beta$ and IL- 6 are reduced in brain blood vessels with increased age. Release of IL-1 $\alpha$, MCP-1, TNF $\alpha$, and IFN- $\gamma$ from brain microvessels also decreases with age. Futhermore, we document that antioxidant protein expression decreases while oxidative stress and release of neurotoxic factors increase in the cerebromicrovasculature with age.

There are conflicting data as to whether indices of inflammation, such as cytokine production, increase, decrease or remain unchanged as humans or animals age $[7,26,27]$. Some reports show an increase in levels of

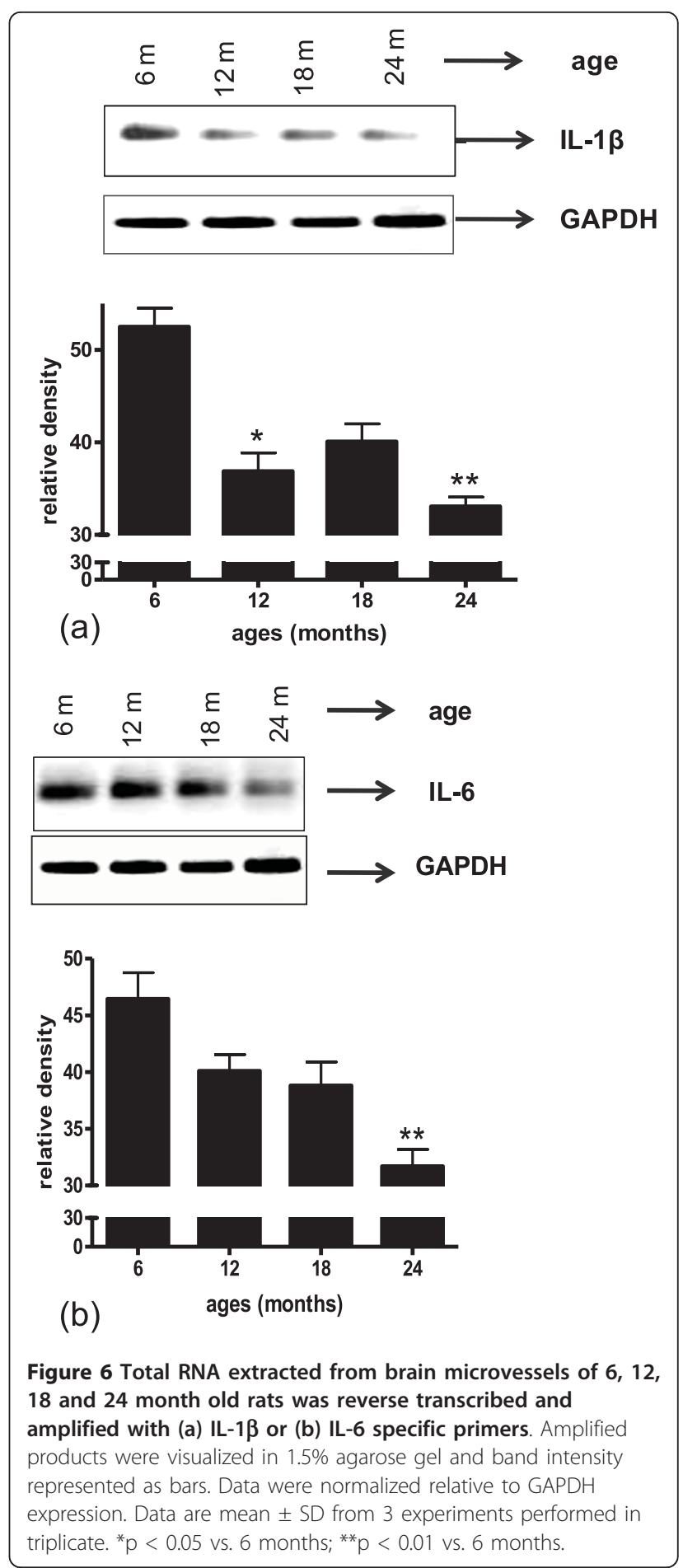

circulating inflammatory proteins in the blood, including TNF $\alpha$ and IL-6, as well as a positive correlation between age and levels of IL-1 $\beta$ in isolated human monocyte cultures stimulated with LPS [3-6,27]. On the other hand, increasing age is associated with a decreased capacity of the immune system to mediate effective immune responses to vaccination and invading pathogens 


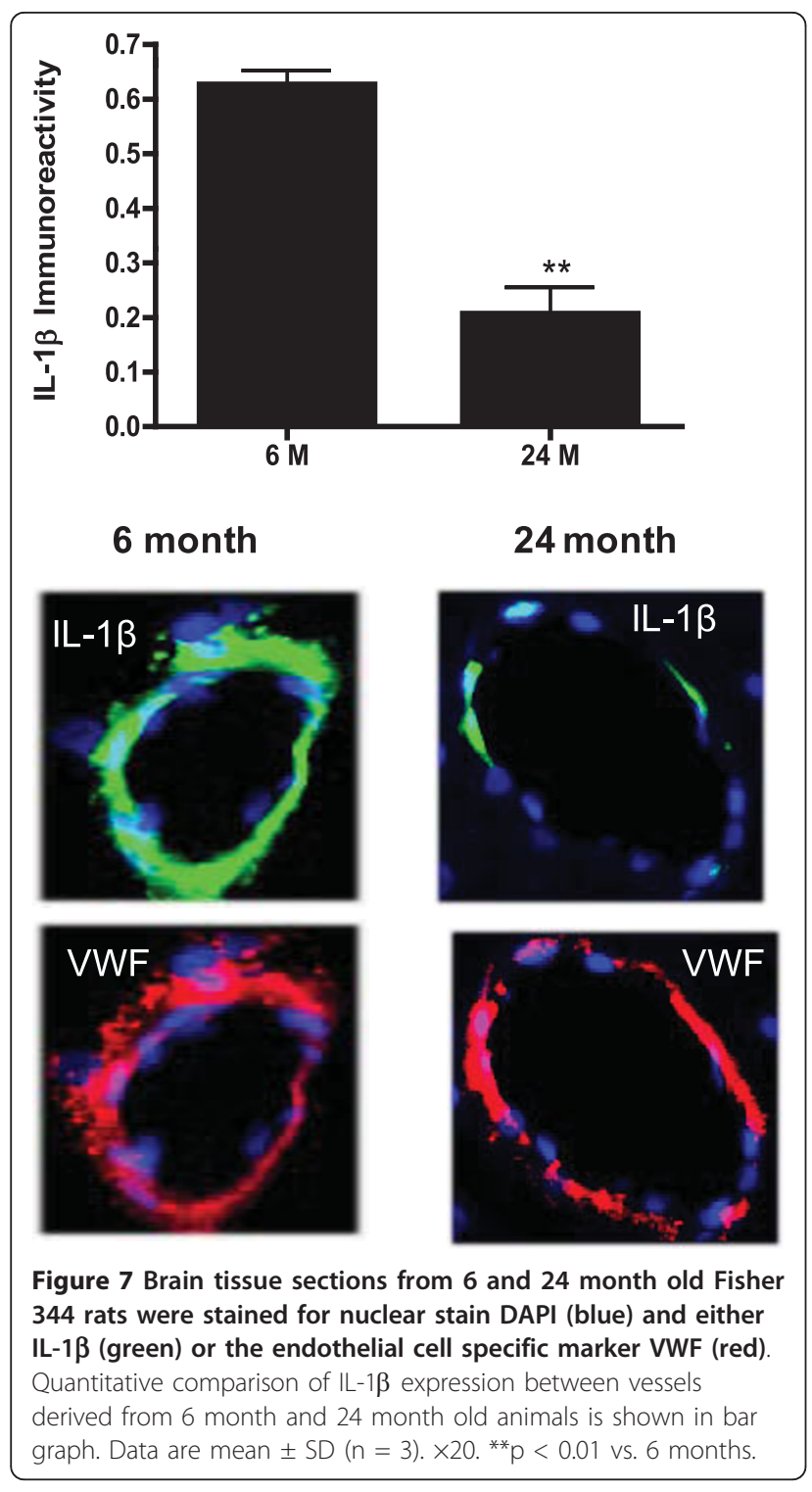

[28-31]. This age-related decrement in immune function is referred to as immunosenescence. Inflammation, a specialized immune response, might be expected to decline with age. In this regard, LPS-stimulated whole blood supernatants from elderly subjects exhibit lower TNF $\alpha$ and IL-1 $\beta$ levels compared to samples from young populations [9]. Differences in the health status of elderly subjects may, in part, explain contradicting results. Most human studies use volunteers that selfreport health status. Thus, elevated IL-6, arguably a potential marker for a variety of diseases, could indicate concomitant inflammatory disease and/or poor nutritional status and indeed has been shown to be elevated in the elderly where C-reactive protein (CRP), an indicator of inflammation, is also high [13]. In this regard, a study where subjects were rigorously screened for good

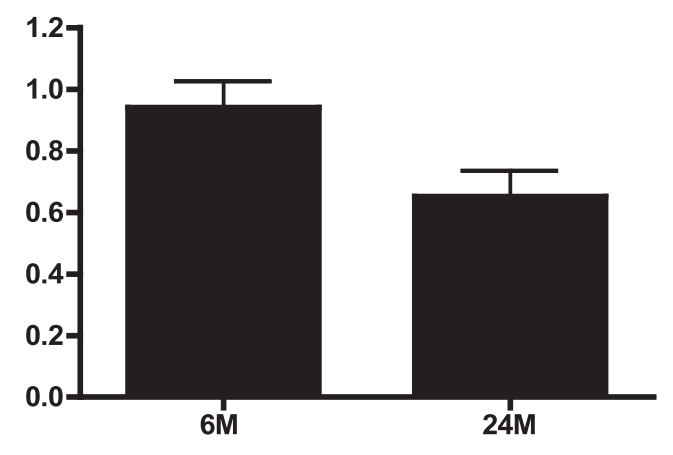

6 month
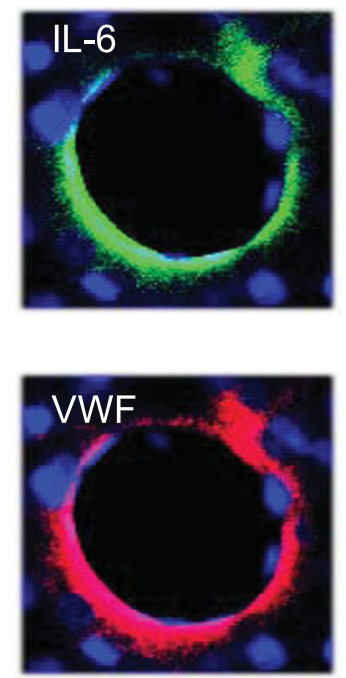

24 month
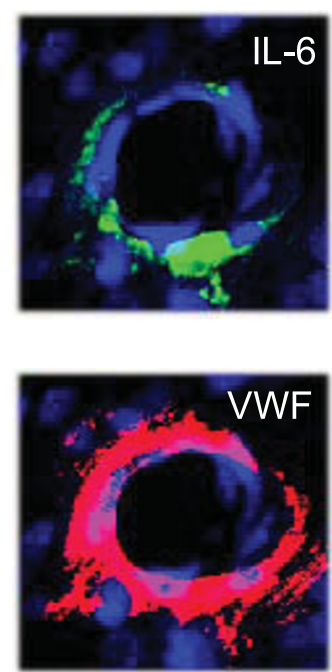

Figure 8 Brain tissue sections from 6 and 24 month old Fisher 344 rats were stained for nuclear stain DAPI (blue) and either IL-6 (green) or the endothelial cell specific marker VWF (red) Quantitative comparison of IL-6 expression between vessels derived from 6 month and 24 month old animals is shown in bar graph. Data are mean \pm SD $(n=3) . \times 20 .{ }^{*} p<0.05$ vs. 6 months.

health found age did not influence basal secretion of IL6 from peripheral blood monocytes (PBMCs), and that stimulated PBMCs from old patients produce less IL-6 than samples from young [7].

Experimental studies in animals that show contradictory alterations in inflammatory mediator expression and release with aging may reflect differences in tissue source and/or cell type. Results of the current study are focused exclusively on brain vascular changes. Comparing expression of IL-1 $\beta$ and IL- 6 between young and old rats we document the decrease in cytokine expression at the RNA level and protein level, using RT-PCR, ELISA and immuno-histochemistry. At the protein level a decrease in IL- $1 \beta$ and IL- 6 is demonstrable both by a rat custom 9 plex assay performed by Pierce Biotechnology, and confirmed in our laboratory by ELISA. 
Table 2 Effect of age on inflammatory proteins released by brain microvessels

\begin{tabular}{lcccc}
\hline $\begin{array}{l}\text { Proteins } \\
\text { (ng/ml) }\end{array}$ & $\begin{array}{c}\mathbf{6} \\
\text { month }\end{array}$ & $\begin{array}{c}\mathbf{1 2} \\
\text { month }\end{array}$ & $\begin{array}{c}\mathbf{1 8} \\
\text { month }\end{array}$ & $\begin{array}{c}\mathbf{2 4} \\
\text { month }\end{array}$ \\
\hline $\mathrm{IL}-1 \alpha$ & $1.87 \pm 0.31$ & $1.53 \pm 0.23$ & $1.13 \pm 0.5$ & $0.47 \pm 0.12^{* *}$ \\
\hline $\mathrm{MCP}-1$ & $12.27 \pm 1.22$ & $7.9 \pm 5.11$ & $2.97 \pm 1.87^{*}$ & $2.07 \pm 1.21^{*}$ \\
\hline $\mathrm{TNF} \alpha$ & $7.40 \pm 1.91$ & $3.20 \pm 1.73^{*}$ & $2.20 \pm 0.0^{* *}$ & $1.87 \pm 0.58^{* *}$ \\
\hline $\mathrm{IFN} \gamma$ & $21.6 \pm 1.40$ & $19.67 \pm 1.47$ & $14.43 \pm 1.78$ & $8.87 \pm 5.99^{* *}$ \\
\hline
\end{tabular}

Microvessels isolated from 6, 12, 18 and 24 month old rat brains were incubated for $8 \mathrm{~h}$ in serum-free media and the supernatant centrifuged $(12,000 \mathrm{~g}, 15 \mathrm{~min})$. Proteins released into the supernatant were determined using rat custom 9 plex array ELISA (Pierce Biotechnology, MA). Data are mean \pm SD from 3 experiments performed in triplicate. ${ }^{*} p<0.05$ vs. 6 month; ** $p<0.01$ vs. 6 month

Although immunohistochemistry is not a quantitative technique, expression of inflammatory proteins is pronounced in the vasculature in brain tissue sections from young animals and is greatly reduced in samples from old rats. These data support the idea that vascularderived IL-1 $\beta$ and IL-6 decrease with age.

Whether specific cytokines are a trophic or toxic influence in the brain is unclear. The cytokines IL-1 $\beta$ and IL- 6 are produced within the CNS, and similar to the periphery, they exhibit pleiotropic and contradictory functions. IL- $1 \beta$ has been identified as a mediator of several forms of neurodegeneration in the brain. Intracerebral administration of IL- $1 \beta$ results in acute brain injury characterized by apoptotic cell death and elevated expression of amyloid beta precursor protein [32]. In rat glial-neuronal cultures IL- $1 \beta$ induces neuronal cell death, via astrocytic release of matrix metalloproteinase9 [33]. In contrast, cultured neurons treated with IL-1 $\beta$ are protected against the neurotoxic effects of NMDAmediated injury; an effect dependent on IL-1 $\beta$-mediated release of nerve growth factor [34]. Also, the protective effect afforded by ischemic preconditioning is associated with an increase in IL- $\beta$, indicating the importance of timing [35]. In a similar manner, IL-6 can produce either deleterious or beneficial effects on neuronal function. IL-6 protects neurons against glutamate- and NMDA excitotoxicity in vitro and prevents brain from ischemic or excitotoxic attacks in vivo $[34,36]$. However, other studies have implicated IL- 6 in the pathogenesis of neurodegenerative disorders [37]. Finally, experiments using neuronal-astrocytic cultures show that IL- 6 is both neuroprotective and neurotoxic, depending on concentration [38]. Taken together, data highlight the importance of context in determining functional significance of inflammatory protein expression.

A consistent literature indicates that oxidative stress is a feature of neurodegenerative diseases and aging [reviewed in [39]]. The oxidative stress-free radical theory of aging proposes that endogenously produced oxygen radicals are a basic cause of progressive age-associated declines in tissue function [40]. In addition, there are complex interactions between inflammatory proteins and oxidative stress. For example, IL- 6 has been shown to protect PC12 neuronal cells from 4hydroxynonenal-induced cytotoxicity by an increase in intracellular glutathione levels [41]. Addition of an antioxidant grape seed extract improves survival of cultured neurons exposed to $\mathrm{H}_{2} \mathrm{O}_{2}$ via release of IL-6 [42]. In the current study we document a progressive increase in vascular carbonyl content with increasing age. Elevated protein carbonyl formation, the most widely studied marker of protein oxidation, has been documented in both normal aging as well as in AD $[39,43]$. Also, oxidative stress reflects an imbalance between reactive species generation and the ability of antioxidant systems to buffer these radicals. An age-related attenuation of microvascular antioxidant defenses has been suggested [44]. Our results show that reactivity to the MnSOD antibody is robust in vessels from young animals, but is barely detectable in vessels of aged Fischer 344 rats. This decrease in the mitochondrial antioxidant MnSOD may be especially relevant for the cerebral microcirculation because endothelial cells have an extensive mitochondrial network [45]. Mitochondria are both sources of and targets for reactive oxygen species, and there is growing evidence that mitochondrial dysfunction may be an important mediator of vascular lesions $[46,47]$. The brain vasculature appears especially sensitive to oxidative stress. This sensitivity may in part be due to higher levels of NAD(P)H-oxidase in brain endothelial cells compared to endothelial cells in peripheral vessels. In this regard, a recent study shows that the inflammatory protein CRP evokes $\mathrm{NAD}(\mathrm{P}) \mathrm{H}$-oxidase dependent functional derangements in brain- but not aorta-derived endothelial cells [48]. Our results, showing a decrease in MnSOD and increase in vascular dysfunction, as evidenced by release of neurotoxins, are supported by studies that link decreased MnSOD with increased endothelial dysfunction $[49,50]$.

Dynamic communication between the cells of the neurovascular unit is required for normal brain functioning [51]. Endothelial cells are a key component of the neurovascular unit and are highly synthetic cells. Activated endothelial cells elaborate adhesion molecules, cytokines, chemokines growth factors, vasoactive molecules, procoagulant and anticoagulants moieties and variety of other gene products with biologic activity. The activated endothelium exerts direct local effects by producing paracrine factors that act on adjacent cells [52]. Pathologically activated or dysfunctional endothelial cells are key to the development of the age-associated cardiovascular disease atherosclerosis and are increasingly implicated in the development of disorders of the CNS [53]. We have shown synthesis and release of neurotoxic thrombin 
from the cerebro-microcirculation in $\mathrm{AD}$ [25]. In the current study we document that aging, in the absence of disease, causes changes in brain blood vessels that result in release of factors that are injurious to neurons. These data highlight a role for vascular-derived products as contributing to a noxious microenvironement for neurons in the aging brain. Understanding how aging affects vascular expression of inflammatory proteins, oxidative stress markers, and neurotoxins could provide insight into how aging predisposes the brain to development of age-related diseases and suggest strategies to improve brain function in aging.

\section{Acknowledgements}

Sources of support: This work was supported in part by grants from the National Institutes of Health (AG15964, AG020569 and AG028367). Dr. Grammas is the recipient of the Shirley and Mildred Garrison Chair in Aging The authors gratefully acknowledge the secretarial assistance of Terri Stahl.

\section{Authors' contributions}

DT carried out the protein carbonyl studies, the ELISA and RT-PCR studies, the western blot analysis, participated in the microvessel isolation and cell culture procedures, ran statistical analysis on the gathered data and created the initial manuscript draft. XY performed the immunofluorescence studies and analysis. AS performed the microvessel isolation and cell culture procedures. $J \mathrm{~L}$ participated in the design and coordination of the study as well as revised the manuscript for intellectual content. JM aided in the drafting of the manuscript and participated in the revision of the manuscript for intellectual content as well as the interpretation of data. PG is the laboratory $\mathrm{Pl}$, participated in the design and coordination of the study, aided in drafting the manuscript, revised the manuscript for intellectual content, interpreted data and gave final approval of the manuscript. All authors read and approved the final manuscript.

\section{Competing interests}

All authors have contributed to the work and agree with the presented findings. This work has not been published before nor is it being considered for publication by another journal. There is no conflict of interest with any of the authors.

Received: 1 July 2010 Accepted: 11 October 2010

Published: 11 October 2010

\section{References}

1. Sarkar D, Fisher PB: Molecular mechanisms of aging-associated inflammation. Cancer Lett 2006, 236:3-23.

2. Galasko D, Montine TJ: Biomarkers of oxidative damage and inflammation in Alzheimer's disease. Biomark Med 2010, 4:27-36.

3. Ershler WB, Keller ET: Age-associated increased interleukin-6 gene expression, late-life diseases, and frailty. Annu Rev Med 2000, 51 245-270.

4. Ershler WB, Sun WH, Binkley N, Gravenstein S, Volk MJ, Kamoske G, Klopp RG, Roecker EB, Daynes RA, Weindruch R: Interleukin-6 and aging: blood levels and mononuclear cell production increase with advancing age and in vitro production is modifiable by dietary restriction. Lymphokine Cytokine Res 1993, 12:225-230

5. Paganelli R, Di lorio A, Patricelli L, Ripani F, Sparvieri E, Faricelli R, larlori C, Porreca E, Di Gioacchino M, Abate G: Proinflammatory cytokines in sera of elderly patients with dementia: levels in vascular injury are higher than those of mild-moderate Alzheimer's disease patients. Exp Gerontol 2002, 37:257-263.

6. Wei J, Xu H, Davies JL, Hemmings GP: Increase of plasma IL-6 concentration with age in healthy subjects. Life Sci 1992, 51:1953-1956.

7. Beharka AA, Meydani M, Wu D, Leka LS, Meydani A, Meydani SN: Interleukin-6 production does not increase with age. J Gerontol A Biol Sci Med Sci 2001, 56:B81-B88.
8. Peterson PK, Chao CC, Carson P, Hu S, Nichol K, Janoff EN: Levels of tumor necrosis factor alpha, interleukin-6, interleukin-10 and transforming growth factor beta are normal in the serum of the healthy elderly. Clin Infect Dis 1994, 19:1158-1159.

9. Bruunsgaard H, Pedersen AN, Schroll M, Skinhøj P, Pedersen BK: Impaired production of proinflammatory cytokines in response to lipopolysaccharide (LPS) stimulation in elderly humans. Clin Exp Immunol 1999, 118:235-241

10. Csiszar A, Ungvari Z, Koller A, Edwards JG, Kaley G: Aging-induced proinflammatory shift in cytokine expression profile in rat coronary arteries. FASEB J 2003, 17:1183-1185.

11. Swift ME, Burns AL, Gray KL, DiPietro LA: Age-related alterations in the inflammatory response to dermal injury. J Invest Dermatol 2001, 117:1027-1035.

12. Pérez V, Velarde V, Acuña-Castillo C, Gómez C, Nishimura S, Sabaj V Walter R, Sierra F: Increased kinin levels and decreased responsiveness to kinins during aging. J Gerontol 2005, 60:984-990.

13. Roubenoff $R$, Harris TB, Abad LW, Wilson PWF, Dallal GE, Dinarello CA: Monocyte cytokine production in an elderly population: effect of age and inflammation. J Gerontol A Biol Sci Med Sci 1998, 53:M20-M26.

14. Bujak M, Kweon HJ, Chatila K, Li N, Taffet G, Frangogiannis NG: Agingrelated defects are associated with adverse cardiac remodeling in a mouse model of reperfused myocardial infarction. J Am Coll Cardiol 2008, 51:1384-1392.

15. Emerit J, Edeasm M, Bricaire F: Neurodegenerative diseases and oxidative stress. Biomed Pharmacother 2004, 58:39-46

16. Finkel T, Holbrook NJ: Oxidants, oxidative stress and biology of aging. Nature 2000, 408:239-247.

17. Møller P, Løhr M, Folkmann JK, Mikkelsen L, Loft S: Aging and oxidatively damaged nuclear DNA in animal organs. Free Radic Biol Med 2010, 48:1275-1285.

18. Grammas $P$, Ovase R: Inflammatory factors are elevated in brain microvessels in Alzheimer's disease. Neurobiol Aging 2001, 22:837-842.

19. Grammas $P$, Ovase R: Cerebrovascular TGF- $\beta$ contributes to inflammation in the Alzheimer's brain. Am J Pathol 2002, 160:1583-1587

20. Grammas P, Samany PG, Thirmangalakudi L: Thrombin and Inflammatory proteins are elevated in Alzheimer's disease microvessels: Implications for disease pathogenesis. J Alzheimers Dis 2006, 9:51-58.

21. Dorheim MA, Tracey WR, Pollock JS, Grammas P: Nitric oxide is elevated in Alzheimer's brain microvessels. Biochem Biophys Res Comm 1994, 205:659-665.

22. Grammas $\mathrm{P}$, Moore $\mathrm{P}$, Weigel PH: Microvessels from Alzheimer's disease brains kill neurons in vitro. Am J Pathol 1999, 154:337-342.

23. Diglio CA, Grammas P, Giacomelli F, Wiener J: Primary culture of rat cerebral microvascular endothelial cells. Lab Invest 1982, 46:554-563.

24. Reimann-Philips U, Ovase R, Lapus M, Weigel PH, Grammas P: Mechanisms of cell death in primary cortical neurons and PC12 cells. J Neurosci Res 2001, 64:654-660.

25. Yin $X$, Wright J, Wall T, Grammas P: Brain endothelial cells synthesis neurotoxic thrombin in Alzheimer's disease. Am J Path 2010, 176:1600-1606

26. Effros RB, Svoboda K, Walford RL: Influence of age and caloric restriction on macrophage IL-6 and TNF production. Lymphokine Cytokine Res 1991 10:2375-2378.

27. Krabbe KS, Pedersen M, Bruunsgaard H: Inflammatory mediators in the elderly. Exp Gerontol 2004, 39:687-699.

28. Frasca D, Landin AM, Riley RL, Blomberg BB: Mechanisms for decreased function of B cells in aged mice and humans. J Immunol 2008, 180:2741-2746

29. Goldmann O, Lehne S, Medina E: Age-related susceptibility to Streptococcus pyogenes infection in mice: underlying immune dysfunction and strategy to enhance immunity. J Pathol 2010, 220:521-529.

30. Kovaiou RD, Herndler-Brandstetter D, Grubeck-Loebenstein B: Age-related changes in immunity: implications for vaccination in the elderly. Expert Rev Mol Med 2007, 9:1-17.

31. Maue AC, Yager EJ, Swain SL, Woodland DL, Blackman MA, Haynes L: T-cell immunosenescence: lessons learned from mouse models of aging. Trends Immunol 2009, 30:301-305. 
32. Fan LW, Mitchell HJ, Tien LT, Rhodes PG, Cai Z: Interleukin-1beta-induced injury in the neonatal rat can be ameliorated by alpha-phenyl-n-tertbutyl-nitrone. Exp Neurol 2009, 220:13-153.

33. Thornton P, Pinteaux E, Allan SM, Rothwell NJ: Matrix metalloproteinase- 9 and urokinase plasminogen activator mediate interleukin-1-induced neurotoxicity. Mol Cell Neurosci 2008, 37:135-142.

34. Carlson NG, Wieggel WA, Chen J, Bacchi A, Rogers SW, Gahring LC: Inflammatory cytokines IL-1a, IL-1 $\beta$, IL- 6 and TNF- $\alpha$ impart neuroprotection to an excitotoxin through distinct pathways. $J$ Immunol 1999, 163:3963-3968.

35. Shin JA, Park EM, Choi JS, Seo SM, Kang JL, Lee KE, Cho S: Ischemic preconditioning-induced neuroprotection is associated with differential expression of IL-1beta and IL-1 receptor antagonist in the ischemic cortex. J Neuroimmunol 2009, 217:14-19.

36. Wang $X Q$, Peng YP, Lu JH Cao BB, Qui YH: Neuroprotection of interleukin6 against NMDA attack and its signal transduction by JAK and MAPK. Neurosci Lett 2009, 450:122-126.

37. Sawada M, Imamura K, Nagatsu T: Role of cytokines in inflammatory process in Parkinson's disease. J Neural Transm Suppl 2006, 70:373-381.

38. Li XZ, Bai LM, Yang YP, Luo WF, Hu WD, Chen JP, Mao CJ, Liu CF: Effects of IL-6 secreted from astrocytes on the survival of dopaminergic neurons in lipopolysaccharide-induced inflammation. Neuorsci Res 2009, 65:252-258.

39. Beal MF: Oxidatively modified proteins in aging and disease. Free Rad Biol Med 2002, 32:797-803.

40. Ames BN, Shigenaga MK, Hagen TM: Oxidants, antioxidants, and the degenerative diseases of aging. Proc Natl Acad Sci USA 1993, 90:7915-7922.

41. Nakajima A, Yamada K, Zou LB, Yan Y, Mizuno M, Nabeshima T: Interleukin6 protects PC12 cells from 4-hydroxynonenal-induced cytotoxicity by increasing intracellular glutathione levels. Free Radic Biol Med 2002, 32:1324-1332.

42. Fujishita K, Ozawa T, Shibata K, Tanabe S, Sato Y, Hisamoto M, Okuda T, Koizumi S: Grape seed extract acting on astrocytes reveals neuronal protection against oxidative stress via interleukin-6-mediated mechanisms. Cell Mol Neurobiol 2009, 29:1121-1129.

43. Levine RL: Carbonyl modified proteins in cellular regulation, aging, and disease. Free Radic Biol Med 2002, 32:790-796.

44. Williams WM, Chung YW: Evidence for an age-related attenuation of cerebral microvascular antioxidant response to oxidative stress. Life Sci 2006, 79:1638-1644.

45. Dranka BP, Hill BG, Darley-Usmar VM: Mitochondrial reserve capacity in endothelial cells: The impact of nitric oxide and reactive oxygen species. Free Radic Biol Med 2010, 48:905-914.

46. Puddu P, Puddu GM, Cravero E, De Pascalis S, Muscari A: The emerging role cardiovascular risk factor-induced mitochondrial dysfunction in atherogenesis. J Biomed Sci 2009, 16:112-121.

47. Victor VM, Rocha M: Targeting antioxidants to mitochondria: a potential new therapeutic strategy for cardiovascular diseases. Curr Pharm Des 2007, 13:845-863.

48. Closhen D, Bender B, Luhmann HJ, Kuhlmann CRW: CRP-induced levels of oxidative stress are higher in brain than aortic endothelial cells. Cytokine 2010, 50:117-120.

49. Brown KA, Didion SP, Andresen JJ, Faraci FM: Effect of aging, MnSOD deficiency, and genetic background on endothelial function: evidence for MnSOD haploinsufficiency. Arterioscler Thromb Vasc Biol 2007 27:1941-1946

50. Wenzel P, Schuhmacher S, Kienhöfer J, Müller J, Hortmann M, Oelze M, Schulz E, Treiber N, Kawamoto T, Scharffetter-Kochanek K, Münzel T, Bürkle A, Bachschmid MM, Daiber A: Manganese superoxide dismutase and aldehyde dehydrogenase deficiency increase mitochondrial oxidative stress and aggravate age-dependent vascular dysfunction. Cardiovasc Res 2008, 80:280-289.

51. Bell RD, Zlokovic BV: Neurovascular mechanisms and blood-brain barrier disorder in Alzheimer's disease. Acta Neuropathol 2009, 118:103-113.

52. Gimbrone MA Jr, Topper JN, Nagel T, Anderson KR, Garcia-Cardena G: Endothelial dysfunction, hemodynamic forces, and atherogenesis. Ann NY Acad Sci 2000, 902:239-240.

53. Zlokovic BV: The blood-brain barrier in health and chronic neurodegenerative disorders. Neuron 2008, 57:178-201. doi:10.1186/1742-2094-7-63

Cite this article as: Tripathy et al: Cerebrovascular expression of proteins related to inflammation, oxidative stress and neurotoxicity is altered with aging. Journal of Neuroinflammation 2010 7:63.

\section{Submit your next manuscript to BioMed Central and take full advantage of:}

- Convenient online submission

- Thorough peer review

- No space constraints or color figure charges

- Immediate publication on acceptance

- Inclusion in PubMed, CAS, Scopus and Google Scholar

- Research which is freely available for redistribution

Submit your manuscript at www.biomedcentral.com/submit 